
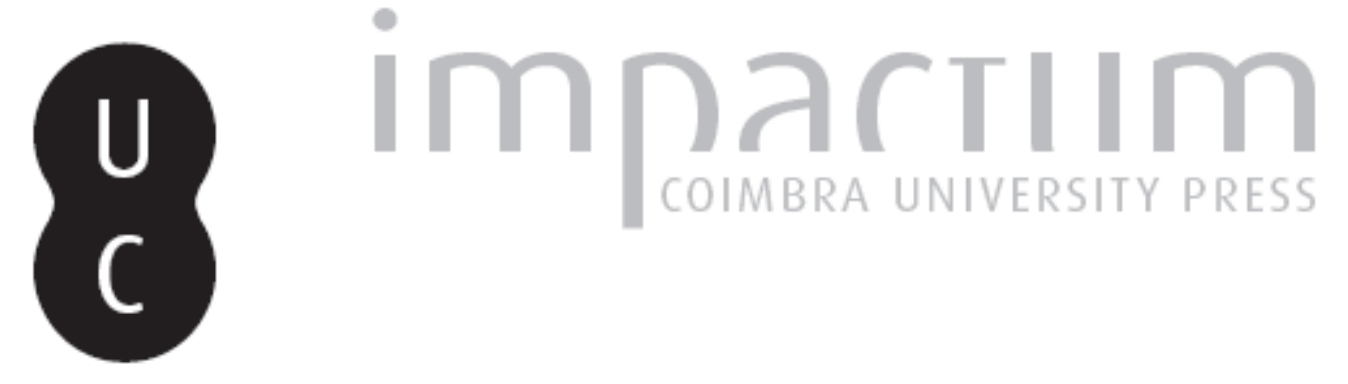

\title{
Erosão e paisagem em São Vicente e Santo Antão (Cabo Verde): o risco de desertificação
}

Autor(es): $\quad$ Martins, Bruno; Rebelo, Fernando

Publicado por: Associação Portuguesa de Riscos, Prevenção e Segurança

URL

persistente:

URI:http://hdl.handle.net/10316.2/36149

DOI:

DOI:http://dx.doi.org/10.14195/1647-7723_16_7

Accessed : $\quad$ 26-Apr-2023 13:02:56

A navegação consulta e descarregamento dos títulos inseridos nas Bibliotecas Digitais UC Digitalis, UC Pombalina e UC Impactum, pressupõem a aceitação plena e sem reservas dos Termos e Condições de Uso destas Bibliotecas Digitais, disponíveis em https://digitalis.uc.pt/pt-pt/termos.

Conforme exposto nos referidos Termos e Condições de Uso, o descarregamento de títulos de acesso restrito requer uma licença válida de autorização devendo o utilizador aceder ao(s) documento(s) a partir de um endereço de IP da instituição detentora da supramencionada licença.

Ao utilizador é apenas permitido o descarregamento para uso pessoal, pelo que o emprego do(s) título(s) descarregado(s) para outro fim, designadamente comercial, carece de autorização do respetivo autor ou editor da obra.

Na medida em que todas as obras da UC Digitalis se encontram protegidas pelo Código do Direito de Autor e Direitos Conexos e demais legislação aplicável, toda a cópia, parcial ou total, deste documento, nos casos em que é legalmente admitida, deverá conter ou fazer-se acompanhar por este aviso.

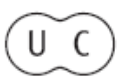




\section{territorium}

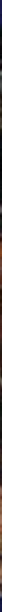

16

Revista da Associação Portuguesa de Riscos, Prevenção e Segurança 2009 
territorium 16

\title{
EROSÃO E PAISAGEM EM SÃO VICENTE E SANTO ANTÃO (CABO VERDE) : O RISCO DE DESERTIFICAÇÃO*
}

\author{
Brumo Martins \\ ceógrafo. Universidade Portucalense, Porto \\ geogbruno@gmail.com \\ Fernando Rebelo \\ Professor Catedrático. Departamento de Geografia da Faculdade de Letras da Universidade de Coimbra \\ fsrebeloeci.uc.pt
}

\section{RESUMO}

A desert ificação é um processo complexo, resultante da interacção entre ambiente e acção antrópica. É de difícil definição territorial e solução. Os ecossistemas secos são particularmente vulneráveis a qualquer actuação, exigindo uma ocupação do solo bem estudada e adaptada às condiçães específicas do quadro geográfico presente. Em Cabo Verde, emparticular nas ilhas de São Vicente e de Santo Antão, são variados as indícios de perda de capacidade produtiva dos solos. A agricultura de sequeiro e a de regadio enfrentam problemas específicos de produtividade, relativas à vulnerabilidade intrínseca das áreas ande se inserem e do sistema produtivo. Neste artigo são analisadbs alguns desses problemas e algumas soluçães de forma a mitigar o risco de contínua perda de produtividade do solo devida à desert ificação.

Palavras chave: Cabo Verde, São Vicente, Santo Antão, erosão, desertificação.

\section{RÉSUMÉ}

La désertification est une question complexe, résultant de l'interaction entre enviromenent et action humaine. Elle est de localisation et solution difficile. Ies écosystènes secs sont partiaulièrenent vulnérables saus quelque actuation de l'homme. Donc, une ocaupation du sol dbit être bien étudiée et adaptée aux conditions spécifiques de l'encadrement géographique. Aux îles du Cap Vert, en particulier São Vicente et. Santo Antão, les indices de perte de capacitéprodutive des sols sont très variés. L'agrialture, soit de jachère, soit d'imigation, est confrantée avec des problèmes spécifiques de productivité, rapportés à la vulnérabilité des aires à elle s' insère et du système productif. Dans cet article sont analysés quelques-uns de ces problèmes, aussi bien que quelques solutions ayant come finalité la mitigation du risque de perte continuée de productivité du sol et de désertification.

Mbts-clé: Cap Vert, São Vicente, Santo Antão, érosion, désertification.

\section{ABSTRACT}

Desertification is a complex process resulting from the interaction between enviroment and human action. It is difficult its territorial defining and solution as well. Dry ecosystems are partiallarly vulnerable to any action. They require a studied land occupation adapted to the specific conditions of the geographical framework in which they qperate. In Cape Verde, and particularly in São Vicente and Santo Antão islands there are several indications of loss of productive capacity of the soil. The dry and irrigated farming faces specific problems of productivity, on the intrinsic vulnerability of the areas where they qperate and of its productive system. This article analyses some of these problems and some solutions in order to mitigate the risk of continuous loss of soil productivity and desertification.

Key words: Cape Verde, São Vicente, Santo Antão, erosion, desertification.

* Comunicação apresentada ao V Encontro Nacional e I Congresso Intemacional de Riscos. 


\section{Introdução}

O arquipélago de Cabo Verde (fig. 1) localiza-se fora da zona de deserto cl inático do hemisfério Norte, embora a doservação de muitas das suas paisagens mostre que se está numa área muito vulnerável aos processas de desert ificação. O eventual agravamento destes processos irá afectar áreas, que poderão juntar-se às paisagens do deserto cl imático.

A acção antrópica pode assumir um papel muito importante na paisagem e na dinâmica de vertentes. o Homem deverá ter em consideração a fragilidade dos ecossistemas secos de forma a não desencadear uma crescente improdutividade do solo, dado que a desert ificação é um problema grave, por vezes, de difícil solução. Geralmente, as ecassistemas secas suavizam consideravelmente a pulsação pluviométrica que sobre eles incide. Quando existe, a vegetação, batida pelo vento, mas também as solos profundos, as superfícies rochosas entre os solos e os profundos vales aluviais, tendem a armazenar água, contribuindo para que estes ecossistemas, ao aproximarem-se do seu "cl ímax", controlem cada vez melhor o seu próprio micro ambiente (WHITIAKER, 1970). No entanto, a ocupação e uso do solo que não tenha em consideração a particularidade dos ecossistemas secos, muito vulneráveis, poderá desencadear um processo de crescente improdutividade das solos que poderá culminar no processo de desert ificação.

\section{Situação geográfica do arquipélago}

Localizado no oceano Atlântico, a latitudes entre

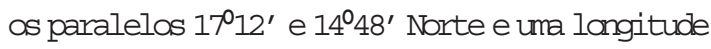
$22^{\circ} 44^{\prime}$ e $25^{\circ} 22^{\prime}$ a Ceste de Greenwich, Cabo Verde insere-se na denominada faixa climática do Sahel, de clima árido e semiárido, que atravessa África desde o Atlântico ao mar Vermelho e se prolonga pela Arábia, Síria e Mesopotâmia, até aos desertos da zona temperada da Eurásia e às regiões subdeserticas afectadas pelos climas monçónicos (C. THORNHHNAIIE, 1948).

Trata-se de uma zona cl imática anticiclánica, que separa a zona quente e húmida intertropical da zona temperada. A chuva é escassa e altamente variável. FonsECA (1962) sobre a irregularidade das chuvas no arquipélago, considerava um período de 23 anos de crises graves de precipitação escassa e um períodb de 11 anos de crises menos graves. Associada a esta irregularidade das precipitações, podemos considerar uma outra característica importante para - problema da erosão e que se relaciona com as características da precipitação. Fm geral, as duvas caem sob a forma de aguaceiros, por vezes, em bátegas fortíssimas, que chegam a atingir valores

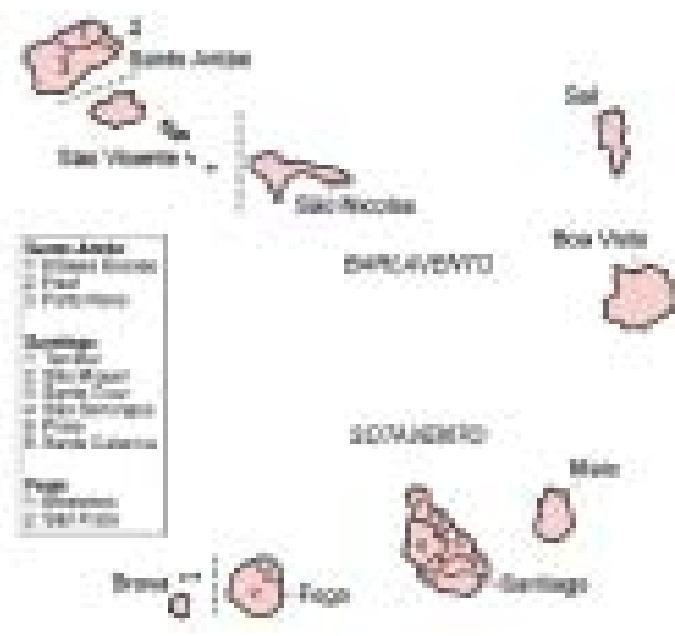

Fig. 1 - Localização da área de estudo no contexto do arquipélago de Cabo Verde.

iguais ou superiores aos valores médios mensais. A época das chuvas compreendida entre Agosto e autubro, podendo ser iniciada, por vezes, em Jilho, corresponde à presença da zona de convergência intertropical, quando esta se encontra mais a Norte

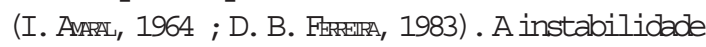
das massas de ar é reforçada pelo efeito orográfico.

A posição do arquipélago de Cabo Verde é marginal à área de grande intensidade convectiva, just ificando a elevada variabi 7 idade da precipitação ao longo dos anos.

Durante a época seca, Cabo Verde está sob influência anticlónica, com ventos a soprar de Nordeste - as alísios. São ventos constantes, que representam uma importante fonte de humidade, principalmente nas vertentes voltadas a Norte e Nordeste, entre os 500 e os 1000 metros de altitude, facto mais relevante nas i thas de Santiago e de Santo Antão. No entanto, mesmo na ilha de São Vicente, em Mbnte Verde, é possível captar água do nevoeiro em quantidades diárias superiores a 100 litros, com méximos de 150 litros. Alguns autores integram estas vertentes nas características de zonas sub-húmidas (Dinzz e Mhros, 1994) . Correspondem grosso modo à plataforma de topo do Monte Verde.

Fntre Dezenbro e Fevereiro é frequente a ocorrência de ventos continentais com uma trajectória de ENE. Estes ventos localmente conhecidbs por "lestadas", são ventos de características secas e quentes, mitas vezes carregados de poeira, provenientes do deserto do Sara, originando aquilo a que se chama "bruma seca" . correspondem ao Harmatão.

\section{Desertificação e provas de desertificação}

A desent ificação é um processso contínuo de perda de produtividade de culturas úteis em áreas secas, 
induzido por modos de vida baseadbs na agricultura e/ou na pecuária, mas também com ligaçães passíveis ao crescimento urbano, com consequências ambientais e sociais importantes. O processo é doservável através do aparecimento de uma paisagem de grande aridez, semelhante mesmo a um deserto, em áreas anteriormente verdes (A. WhHAN e J. MATHAS, 1992) . As áreas desertificadas resultam de processos físicos duradauros, de difícil reaperação, tais cont, em áreas de sequeiro, a erosão dos solos, a degradação do coberto vegetal e dos recursos vegetais, a invasão de areias e a formação de dunas, au, emáreas de regadio, o alagamento e a sal inização.

As situações de crise resultam de alguns anos de seca consecutivos. Os danos causados pelas secas são geralmente resolvidas com intervençães paliativas de arto prazo, ainda que se tome necessário repetilas periodicamente ao longo dos anos. A desertificação tem uma génese mais severa, ligada a processos erosivos que contribuem para a perda de humidade armazenada nos solos, reduzindo a sua disponibilidade para a vegetação, mesmo em anos de maior pluviosidade.

Aúnica prova incontestável de desertificação para uma determinada área seria a que proviesse de campos experimentais, emque todbs os factores com influência na produção, excepto os ambientais, fossem mantidos constantes por um período de tempo nunca inferior a uma década para que abrangesse anos de seca e anos pluviosos (A. WhसRAv e J. MAIZHS, 1992) .

Tais campos não existemnas i has de Cabo Verde. As estatísticas ligadas à produção agrícola são escassas e de fiabilidade duvidasa, alguns inquéritos feitos à população sugerem interpretação dúbia e algumas provas históricas suscitam interpretação diferenciada. O declínio da produção, por exemplo, pode reflectir alteração de mercado, aplicação de técnicas diferentes ou atribuir-se ao processo de desertificação. A própria análise feita a partir da dbservação directa de determinadas características ambientais deve ser muito cautelosa.

No entanto, embora a quantificação e a definição rigorosa das áreas sujeitas ao processo de desertificação sejam difíceis de definirr, numerosas áreas têm sofrido danos severos com natural perda de produtividade e devem ser alvo de processos de combate à desertificação.

\section{Erosão e paisagem}

A perda do potencial produtivo do solo pode ocorrer de duas formas: perda lenta das nutrientes e perda da camada superficial dos solos por erosão, esta ul tima facilmente doservável a partir da formação de ravinas. Geralmente, a doservação de ravinas numa vertente é entendida como uma nuptura no equilíbrio gedbiofísico, que irá necessariamente influenciar a produtividade e exigir estratégias de correcção.

Os métodos de avaliação da perda de capacidade do solo e dos níveis de desertificação são muitos e adoptam diferentes metodologias. São influenciadbs pelo próprio conceito de desertificicação, mas, geralmente, incluem as ravinas nos estádios mais avançadas de desertificação (QHR I) . Nos estádios primitivos de desertificação, os sinais sãomais subtis emais fáceis de corrigir.

Os métoolos de avaliação incluem, por um lado, sinais indicadores de ruptura do equilíbrio do ecossistema e, por attro ladb, bal izadores dos níveis de severidade e recuperação.

No entanto, mesmo os sinais que sugerem risco de desertificação, como a formação de ravinas, podem assumir diferentes interpretações. Um dos mais interessantes é a questão das ravinas, que, paramitos agriaultores, aparecem como uma situação desejável. As ravinas são preenchidas com pedras, que podem funcionar como pequenos muros naturais que retêm tanto o solo cono a água, aumentando a produtividade dos campos. Desempenham função semelhante a pequenas barragens de correcção torrencial construídas há dezenas de anos e que se podem observar, por exemplo, em São Vicente (F. RнBFro, 1999) . Esta perceppção diferenciada do problema dos sinais de desertificação foi analisada por KKसEr (1973) no México e por nós em Cabo Verde.

Os efeitos da erosão são particularmente intensos em ecossistemas secos, com natural impacto na prout tividade doss solos. É frequente os solos encontrarense sem qualquer tipo de cobertura vegetal e as campos agrícolas tomam-se extremamente vulneráveis drranteo períodb de sementeira, no arto períodb das duvas.

O papel da erosão hídrica dos solos é, então, importante na dinâmica das vertentes e no risco de perda de solo.

Os danos causados pelo impacto da chuva dependem da morfologia e das características dos solos. Envolvem três processos:

i o impacto da chuva, que desagrega os solos;

i o encharcamento, que projecta no sentido descendente as partículas dos solos;

iil a escorrência que arrasta partículas, como locbs, argilas e matéria orgânica.

A escorrência é distribuída por tooba a superfície, geralmente a partir de áreas desprovidas de vegetação e posteriormente colectada en depressões. As áreas desprovidas de coberto vegetal absorvem pouca humidade, remetendo-a para áreas onde a água é recebida e onde geralmente a vegetação se desenvolve. A forma como este processo ocorre é variável, dependendo das características geomorfológicas, 
RISCOS - Associação Portuguesa de Riscos, Prevenção e Segurança

QUADRO I - Desertificação crescente. Adaptado de A. WarRRN \& J. MATZHTS (1992)

\begin{tabular}{|c|c|c|c|c|}
\hline & Ligeira & Moderada & Severa & Excessiva \\
\hline $\begin{array}{l}\text { Erosão pela } \\
\text { água }\end{array}$ & $\begin{array}{l}\text { Sulcagem, } \\
\text { regos superficiais }\end{array}$ & $\begin{array}{l}\text { Montículos, } \\
\text { acumulação de lodos }\end{array}$ & $\begin{array}{l}\text { Lavagem } \\
\text { grosseira por } \\
\text { "tubos", } \\
\text { depósitos, } \\
\text { ravinamentos }\end{array}$ & $\begin{array}{l}\text { Acumulação rápida } \\
\text { de lodos nas } \\
\text { albufeiras. } \\
\text { Deslizamentos de } \\
\text { terra. Ravinamentos } \\
\text { extensos. }\end{array}$ \\
\hline $\begin{array}{l}\text { Erosão pelo } \\
\text { vento }\end{array}$ & $\begin{array}{l}\text { Erosão em pequena } \\
\text { escala, superfícies } \\
\text { sulcadas }\end{array}$ & $\begin{array}{l}\text { Montículos formados } \\
\text { pelo vento. } \\
\text { Laminação pelo vento }\end{array}$ & Pavimentos & $\begin{array}{l}\text { Extensão activa de } \\
\text { dunas }\end{array}$ \\
\hline $\begin{array}{l}\text { Erosão pela } \\
\text { água e vento }\end{array}$ & & & Escaldão & Escaldão extenso \\
\hline Terra regada & & $\begin{array}{l}\text { Pequenos trechos } \\
\text { brancos salgados }\end{array}$ & $\begin{array}{l}\text { Grandes trechos } \\
\text { brancos } \\
\text { salgados }\end{array}$ & $\begin{array}{l}\text { Terras inutilizáveis } \\
\text { por excessiva } \\
\text { salinização }\end{array}$ \\
\hline
\end{tabular}

edáficas e clináticas, mas criandb, vistas db ar, áreas ande a vegetação se desenvolve, originandb "faixas", por vezes, densas, separadas por sectores com superfícies completamente desprovidas de vegetação.

Solos de textura mais arenosa são mais permeáveis, diminuindo a escorrência. No entanto, se a sua capacidade for excedida, a sua débil agregação toma-os muito vulneráveis, formandb, por vezes, uma intrincada rede de ravinas (fot. 1) .

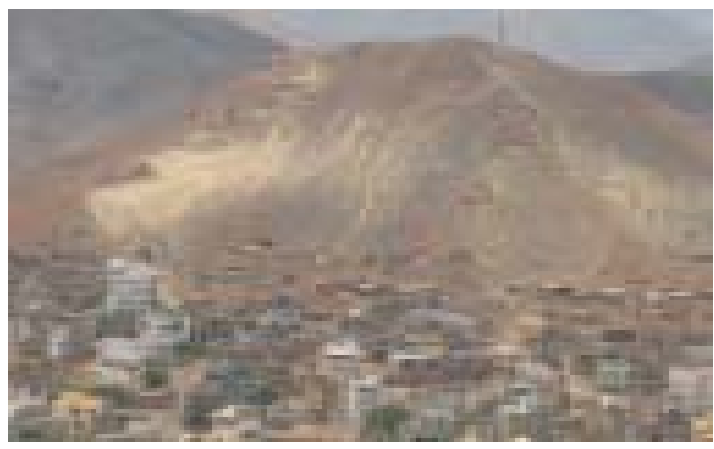

Fot. 1 - Ravinas em areias é́licas - Cruz de Papa (Săo Vicente) .

Os solos argilosos, mais agregados, ocupam geralmente o leito de canais de escorrência esporádica ou de depressões, ligadas a sistemas de drenagempor vezes endorreica (fot. 2) .

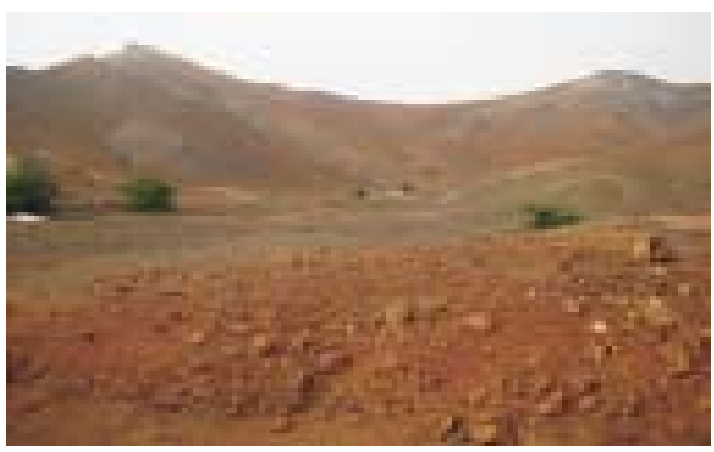

Fot. 2 -Materiais heteramétricas - Mato Inglês (Săo Vicente) .
A escorrência, ocasional, mas geralmente intensa, requer uma rede de drenagem mais extensa para se canalizar. No caso das chuvas intensas, a rede expande-se, formanob-se ravinas, principalmente, nas áreas de maior declive. A formação de ravinas requer material facilmentemobilizável (F. Rmo, 1982), aqui, em geral, depósitos de vertente e areias élicas depositadas. As ravinas de maior dimensão localizamse principalmente nas áreas de sqpé, ande o declive é elevadb e a espessura db rególito permite a existência de ravinas de profundidade métrica (fot. 3) .

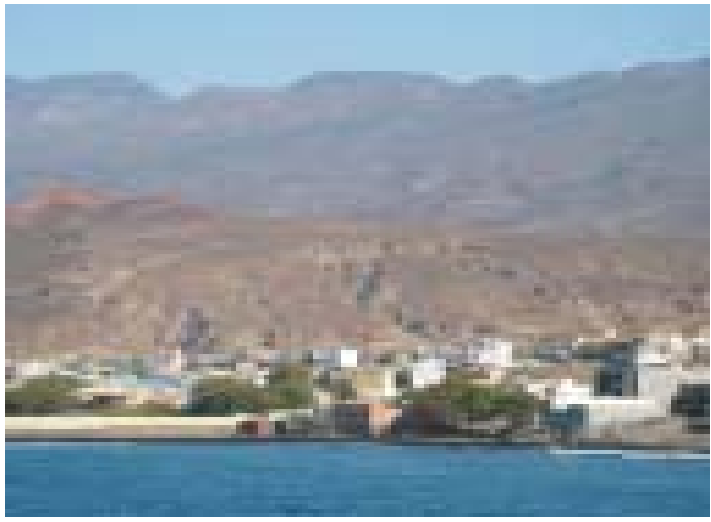

Fot. 3 - Ravinas em áreas de sopé - Porto Novo (Santo Antão) .

O vento altera a morfologia do solo, removendo nutrientes e invadindo áreas marginais com sedimentos. As areias são transportadas pelo vento rente ao solo, lesando culturas e formando pequenas dunas junto a sebes e arlustos, reduzindb a ferti lidade e a capacidade produtiva do solo.

A perda de solo costuma prosseguir até serem atingidas camadas muito duras e cimentadas (fot. 4) . Este processo, muito activo, expande-se consoante a direcção predominante do vento, depositando areias a longas distâncias, funcionando como um deserto em expansão. São particularmente vulneráveis a este 


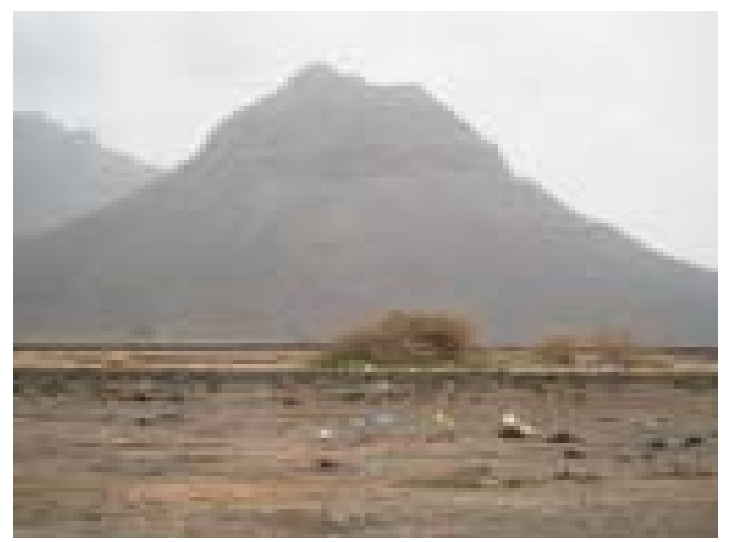

Fot. 4 - Formação de "pavimentos" e dunas - Baía das Gatas (São Vicente) .

fenómeno os solos arenosos, pouco agregados e as áreas de agricultura de sequeiro, frequentemente, desprovidas de vegetação que contrarie o processo.

A forma como os processos de erosão eólica e hídrica se combinam é complexa e depende, naturalmente, de aspectos climáticos, edáficos e morfológicas, bem como de uso e ocupação do solo.

\section{Paisagens na área de estudo - a noção de land-region}

O que propomos na definição de land-region é uma classificação sintética da paisagem que inclui elementos morfológicos, edáficos e de vegetação, resultando de um trabalho realizado a partir da doservação no terreno feita em São Vicente. Tem como objectivo uma classificação da paisagem incluindo ocontexto erosivo.
Vertentes com crosta dura si 7 iciosa

Geralmente as vertentes apresentamperfil côncavo e declive acentuado, com ravinas pouco espaçadas. O solo é caracterizado pela granulometria fina, e por ser pedregoso e muito delgado. A presença de vegetação é nula. Como os solos finos têm poros demasiado pequenos, o poder de absorção das chuvadas intensas é muito reduzido, a escorrência escava sulcos, sendo a forma do relevo uma resposta à acção da água. Novas chuvadas aproximam os pequenos sulcos transformandb-se em ravinas.

\section{Planaltos can crosta si 7 iciosa}

o declive baixo torna a escorrência lenta, aumentando a quantidade de água que se infiltra. A percentagem de cobertura vegetal é variável consoante a quantidade de precipitação e o uso da terra. Os solos apresentam gramulometria fina e espessura variável consoante o uso e ocupação.

\section{Cones de dejecção aluviais}

A presença de ravinas é geralmente muito intensa e os solos apresentam-se muito salinizados, de espessura variável e de textura grosseira. O coberto vegetal é reduzido.

\section{Áreas de planícies com areias sob acção eólica}

Os solos são profundos e de textura arenosa. As infiltrações superam a escorrência. Presença ocasional de água subterrânea em profundidade. A presença da vegetação depende dos valores de precipitação e do uso e ocupação do solo.

QđARro II - Classificação simplificada da paisagens em Cabo Verde

\begin{tabular}{|l|l|l|}
\hline \multicolumn{1}{|c|}{ LAND-REGION } & \multicolumn{1}{|c|}{ EROSÃo PELA ÁGUA } & EROSÃO PELO VENTO \\
\hline $\begin{array}{l}\text { Vertentes com crosta dura } \\
\text { siliciosa }\end{array}$ & $\begin{array}{l}\text { Ravinamentos intensos, } \\
\text { desabamentos, movimentos } \\
\text { em massa }\end{array}$ & Pouca \\
\hline $\begin{array}{l}\text { Planaltos com crosta } \\
\text { siliciosa }\end{array}$ & $\begin{array}{l}\text { Presença de ravinas } \\
\text { espaçadas }\end{array}$ & $\begin{array}{l}\text { Perdas de solos, } \\
\text { formação de pavimentos }\end{array}$ \\
\hline Cones de dejecção aluviais & $\begin{array}{l}\text { Ravinamentos e lavagem } \\
\text { intensos }\end{array}$ & Perdas de solo \\
\hline $\begin{array}{l}\text { Áreas de planícies com } \\
\text { areias sob acção eólica }\end{array}$ & $\begin{array}{l}\text { Incipiente dependendo da } \\
\text { ocupação e uso do solo e } \\
\text { precipitação }\end{array}$ & Formação de dunas \\
\hline Áreas de sopé & $\begin{array}{l}\text { Ravinamentos intensos, } \\
\text { lavagem, depósitos grosseiros }\end{array}$ & Perdas de solo \\
\hline
\end{tabular}


Áreas de sopé

Os solos são geralmente profundos, de textura variada. Depósitos de vertente e complexo sistema de ravinas de dimensão métrica. Perda de solo pela acção é́lica e acumulação de areias com formação de dunas.

\section{Processas perigasas}

O risco de erosão pela chuva em terrenos sem qualquer tipo de protecção é mais elevado nas orlas sub-húmidas, ao passo que a erosão pelo vento constitui risco maior nas áreas mais secas, padrão este que resulta da maior frequência de chuvas concentradas nas áreas mais húmidas e das superfícies pouco compactas e secas das áreas mais áridas.

No entanto, os processos combinam-se, sendo frequente encontrar marcas de erosão hídrica e é́lica endiferentes áreas climáticas nos diferentes sectores das ilhas. A presença de solos pedregasos é frequente em espaças áridas e resulta da combinação da erosão pelo vento e da escorrência, formando pavimentos semelhantes aos desertos.

Nas vertentes sub-húmidas é passível doservar a presença de areias transportadas pelo vento e depósitos de vertentes, ande se desenvolvem ravinas generalizadas, após a queda de precipitação e consequente escorrência, tomando praticamente impossivel o aproveitamento agrícola.

As vertentes com solos delgados têm uma reduzida capacidade de infil tração. Geralmente, uma reduzida precipitação origina elevada quantidade de escorrência e uma diminuta quantidade de água infil trada, disponibilizada à vegetação. As vertentes que são utilizadas para a agriaultura são geralmente regularizadas por socalcos (fot. 5), permitindo o aumento da infiltração e da humidade, contrariando esta tendência. Estas estruturas permitem ainda contrariar o arrastamento do solo e de matéria orgânica após a queda de precipitação, garantindo geralmente, ganhos de produtividade.

A forma como evolui a paisagem e o papel da erosão na capacidade produtiva dos solos depende em larga medida da acção antrópica. Esta deverá ter em consideração a vulnerabilidade dos ecossistemas emterras secas.

Onde, porém, a vegetação se encontre muito espaçada, a protecção que exerce é praticamente nula. A escorrência origina canais e onde o declive se acentua até um certo valor (F. RнHo, L. CNA, A. M. Rochette Corkiro, 1986) formam-se ravinas. Estas paisagens são inteiramente naturais em terrenos acidentados (A. Warren e J. MaIzhes, 1992). A quantidade de solo removido pela escorrência é maior nas regiões semi-áridas do que em qualquer outra parte do mundo (LANGBEIN e SaHum, 1958; FournIER, 1962) . A plantação em vertentes que eventualmente possam ser utilizadas para a agricultura contraria esta tendência e aumenta as reservas úteis do solo.

\section{Modos de vida agrícola}

Apesar da agricultura ocupar apenas 9,6\% da superfície do país, esta actividade representa um dos sectores produtivos primários de maior importância no desenvolvimento socio-econámico de Cabo Verde. Nos anos commelhores resultados agrícolas, quase

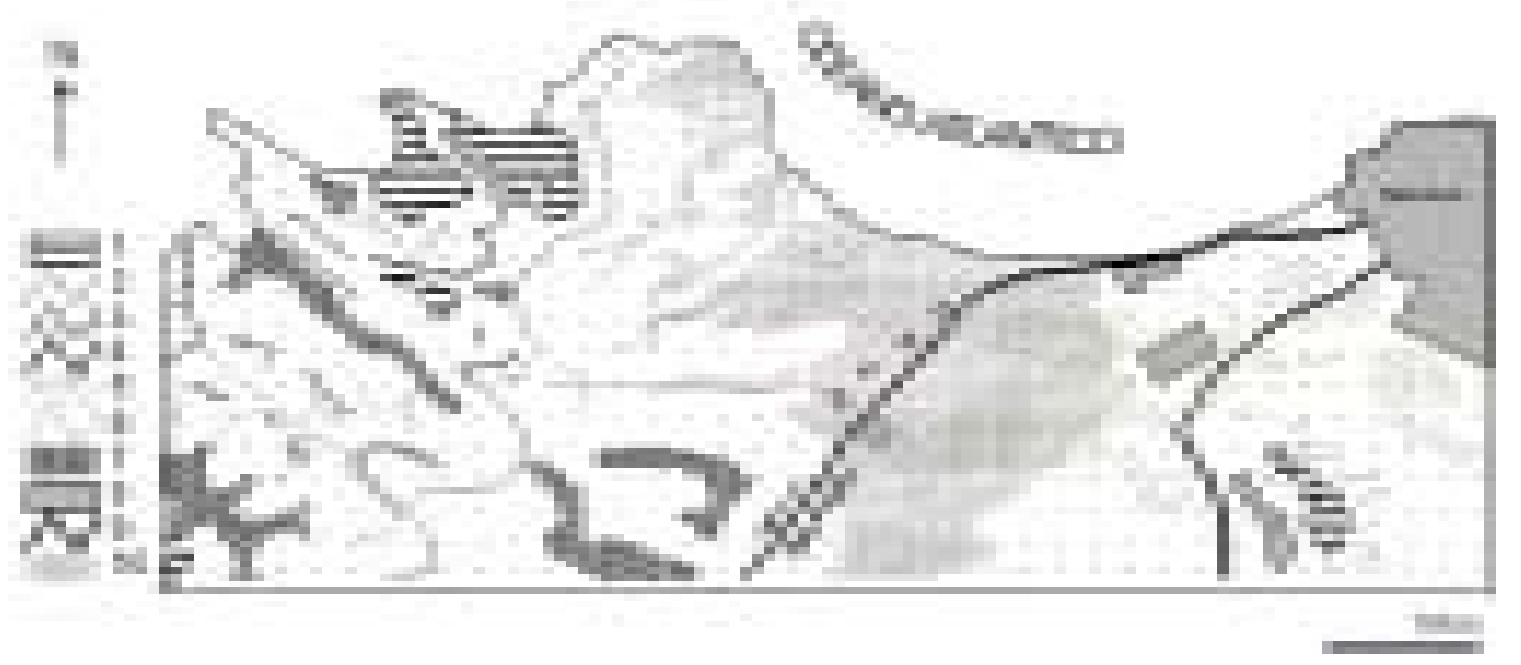

Fig. 2 - Mapa do uso da terra, erosão e sedimentação baseado em fotografias aéreas de 2004 com verificação no terreno - Seç̧ão final da ribeira de Julião (São Vicente) .

Legenda: 1 - Planaltos com crosta siliciosa de perfil concavo. Solos pedregosos delgadas com afloramentos rochosos; 2 - vertentes com crosta dura siliciosa de perfil côncavo, ravinas pouco espaçadas. Solos pedregosos delgados cam afloramentos rochosos; 3 - escarpa; 4 - encaixes profundos; 5 - vegetação; 6 - ravinas; 7 - cones de dejecção aluviais com ravinamento; 8 - habitaçães / cidade; 9 estradas; 10 - areias de acção eólica subterrânea profunda ocasional. Solos profundos arenosos com cobertura vegetal espaçada. 
sempre em função da quantidade e da distribuição espacial e temporal das chuvas, registam-se alterações significativas dos indicadores macroeconómicos, como é o caso da inflação e do poder de compra dos consumidores, através da redução de preços no mercado (SEPA, 2000a; 2000b) .

A nível nacional, a agricultura de sequeiro é largamente a mais praticada, ultrapassando 75\% das explorações. A agricultura de regadio representa apenas 17\% das explorações e as explorações agroflorestais não ultrapassam os 2\%. A ilha de Santo Antão apresenta valores muito próximos da média nacional no que respeita a esta divisão das explorações agrícolas. A ilha de São Vicente, contudo, afasta-se desta distribuição. O número de explorações agrícolas que pratica agricultura de sequeiro não ultrapassa os 6\%. As explorações agrícolas são principalmente de regadio.

Naturalmente que os problemas relacionados com a perda de prooutividade variam em São Vicente e em Santo Antão consoante o tipo de sistema produtivo agrícola. Na primeira, a perda de produtividade está principalmente relacionada com a salinização, a deposição de lamas e o papel destruidor das cheias esporádicas. Os sistemas de rega que recorrem a poços de águas superficiais correm graves riscos de salinização. Em São Vicente a grande maioria dos poços apresenta este tipo de problemas, o que resulta num decréscimo da produção e consequente abandono dos campos agrícolas. As populações deslocam-se de imediato para a cidade de Mindelo ou procuram a emigração na esperança de melhoria das condições de vida.

A utilização de água para rega obtida a partir da EIAR da Vinha, tem vindo a mitigar este problema e a impulsionar o aumento do número de exploraçães fixando população nas ribeiras da Vinha e de Jilião, através da agricultura. Actualmente, o número das explorações que obtêm água a partir da ETAR já ultrapassa as 40\%.

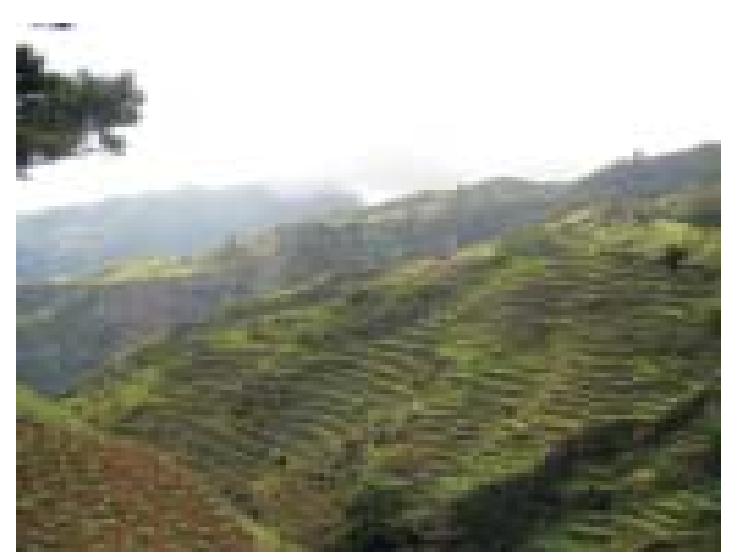

Fot. 5 - Construção de socalcos - NE de Santo Antão.
No entanto, os investimentos feitos são elevados, exigindb por vezes o rearso a créditos, o que afasta alguns investidores. Por exemplo, a técnica de distriburição de rega éogotejamento (fot. 6) , envolvendb uma disposição de tubagens para o transporte da água e levando a investimentos avultados, tanto de início, como posteriormente, em manutenção.

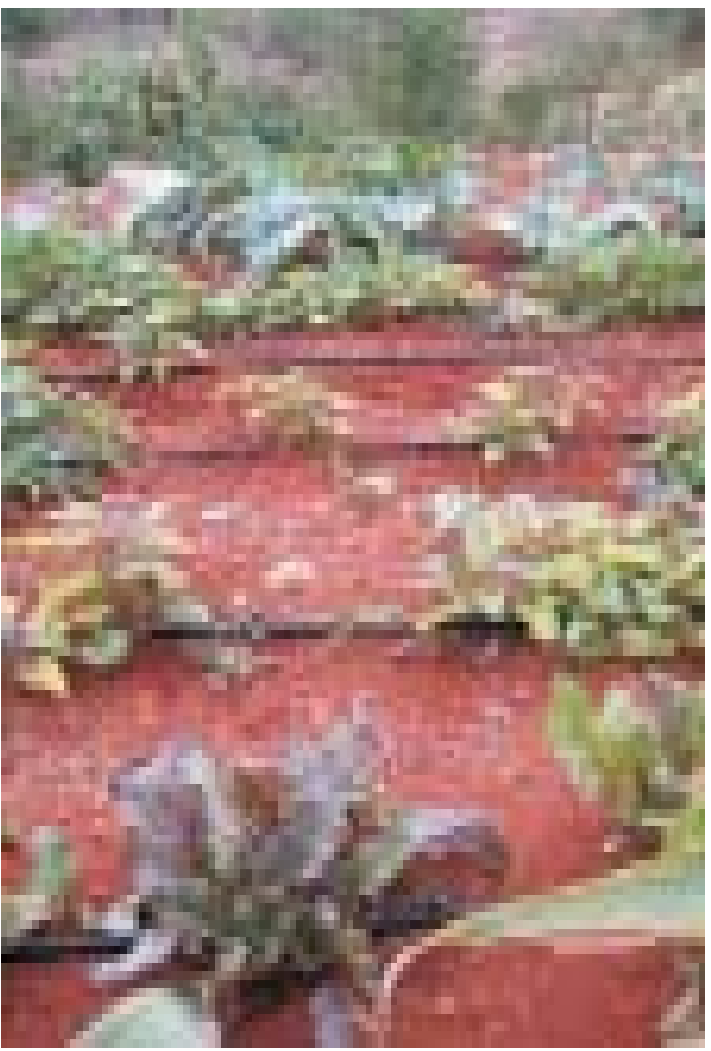

Fot. 6 - Sistema de rega de gotejamento distribuída por tubagens - Ribeira da Vinha (São Vicente) .

O método consiste em libertar água em pontos estratégicos localizados perto das raízes e com intervalos frequentes. Possibilita, ainda, ajustar o formecimento de água à capacidade de absorção do solo e às necessidades sazonais das culturas. Em consequência, a prooução tem vindo a aumentar e é mais regular. En visita a algumas exploraçães e em contacto com agricultores locais, concluiu-se que o nível geral de satisfação é elevado.

A agricultura de sequeiro predomina largamente em Santo Antão. As estratégias e técnicas adoptadas têm vindo a responder aos problemas relacionados com a variabilidade da precipitação, adoptando estratégias e técnicas que visam maximizar a humidade. É, ainda, frequente a combinação do cultivo com a colecta e exploração agro-pecuária, principalmente em pequenas explorações.

Uira autra resposta à variabi l idade pluviométrica com repercussão directa na produção, é o recurso 
ao artesanato, a algumas actividades transformadoras e à pesca. Pensamos que o artesanato poderá ser mais explorado e articulado com os mercadbs locais, regionais e intemacionais. As técnicas ut i i izadas para dbtenção de produções mais elevadas baseiam-se ainda no tipo de sementes, geralmente melhoradas, o estrume, a uti 7 ização de terras húmidas das extremidades dos vales e a constnução de socalcas, diques (fot. 7) e represas que proarram contrariar os prejuízos associados à escorrência.

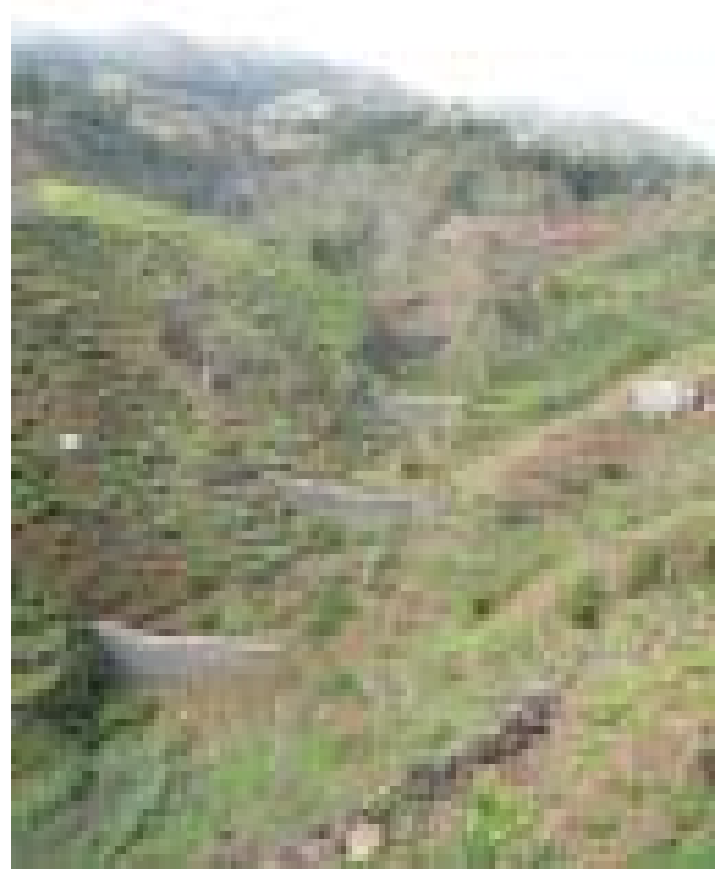

Fot. 7 - Construção de diques - NE de Santo Antão.

Em termos gerais, o papel dos socalcos no controlo da desertificicação é benéfico. Impede a perda de solo por escorrência em períodos de forte precipitação, contrariando o arrastamento do solo e da matéria orgânica, melhorandb a sua fertilidade. A construção de represas em cursos de água efémeros contribui, também, para o cultivo da terra que, de autro modb, não seria possível.

O processo de degradação destes socalcos é geralmente associado ao abandono da prática agrícola e, bem mais depressa do que noutras latitudes (L. Lakenș, 2006), evolui rapidamente numa crescente degradação ambiental.

Em Santo Antão, os problemas ligados à desert ificação e aos custos de produção em sistema de regadio são menores. A maioria das exploraçães utiliza água de nascente, transportando-a principalmente em levada aberta de cimento, evitanob a acumulação de sais no solo.

\section{Enfrentandb a desertificação}

As principais consequências da desertificicação são a baixa da produtividade do recurso-base, as ameaças à saúde e ao bem-estar da população sujeita ao risco, tal como os problemas causados pelas migrações, quandb o risco se manifesta em toda a sua plenitude. Após anos de seca, todavia, a população nural, que na sua maioria vive da agricultura, irá certamente ultrapassar a crise e a vida no campo continuará a ser viável económica e socialmente. No entanto, uma boa parte migrará em definitivo para os principais centros unbanos ou para o exterior do país.

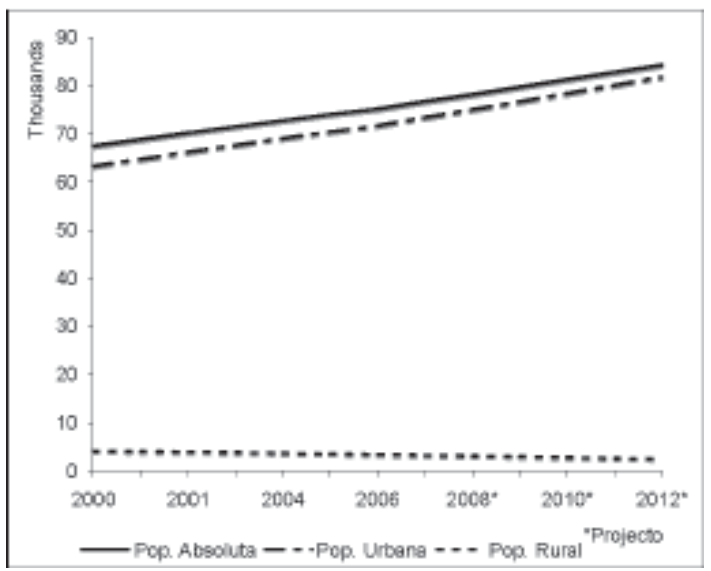

Fig. 3 - Evolução da população absoluta, rural e urbana em São Vicente (INE, 2008 - Censos 2000 ajustados)

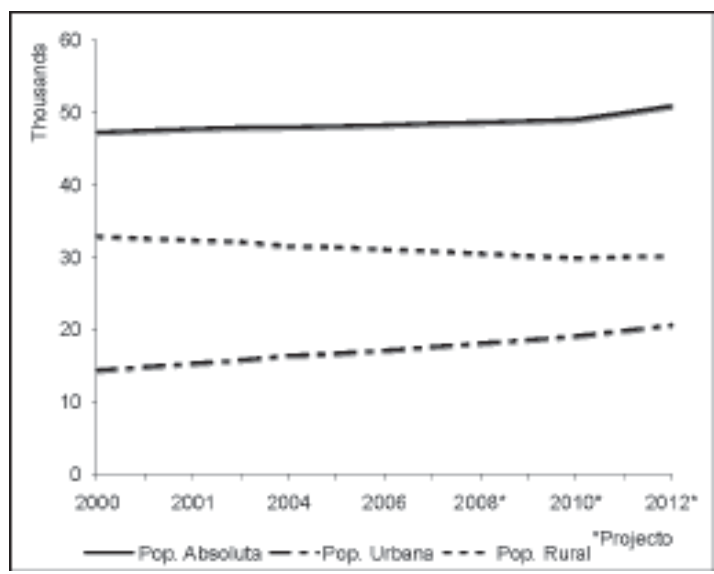

Fig. 4 - Evolução da população absoluta, rural e urbana em Santo Antão (INE, 2008 - Censos 2000 ajustados)

A relação entre anos de secas e aumento do êxodo nural deverá continuar a ser estudada em cabo Verde, dada a sua importância. A tendência do crescimento urbano no arquipélago, principalmente nas duas principais cidades, Praia e Mindelo, tem vindo a aumentar ao longo dos anos. No entanto, não temos conhecimento de estudbs recentes acerca deste crescimento e da sua relação com anos de seca. 


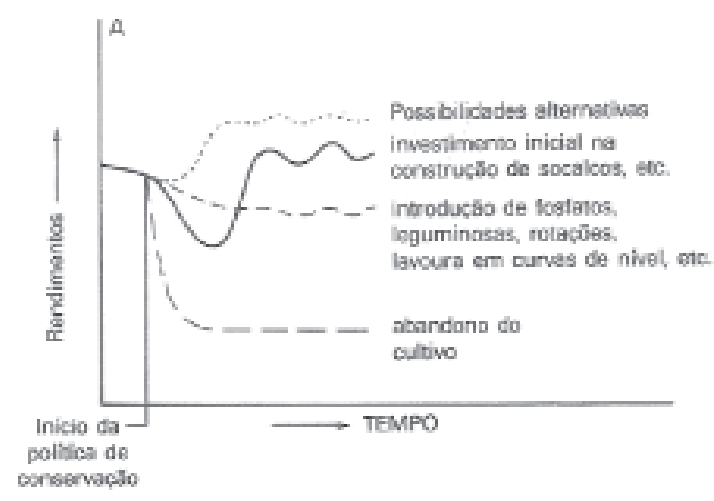

Fig. 5 - Políticas de intervenção e produtividade em áreas de sequeiro (A. WhRPRN e J. MATZHS, 1992) .

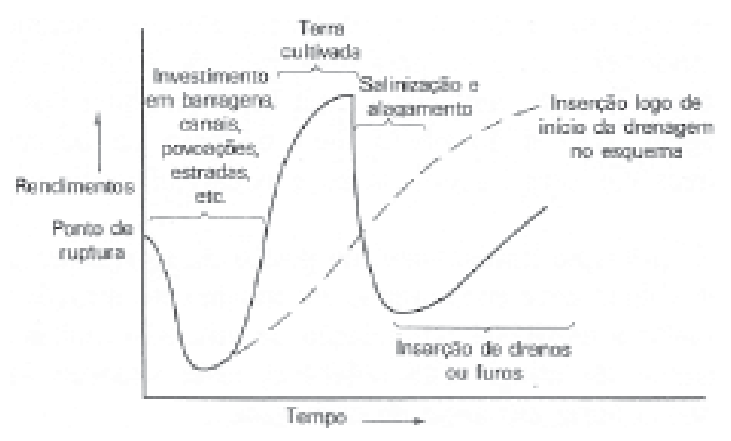

Fig. 6 - Políticas de intervenção e produtividade em áreas de regadio (A. WarRen e J. MAIZZLS, 1992).

O contacto estabelecido com a população em São Vicente e Santo Antão, quer em áreas nurais quer em áreas urbanas, confirma o sentimento de seca e desertificação associadb às áreas nurais em contraste com a perspectiva de que as cidades e principalmente a emigração funcionam como veículo de mais e melhores oportunidades, empregos e remuneração.

O crescimento das cidades, muito acelerado, não é acompanhado do planeamento das mesmas, agravado por uma crescente necessidade de água, recurso escasso e dispendioso.

Desta forma, o princípio para mitigar os problemas urbanos e o processo de degradação e desert ificação das áreas rurais passa por uma distribuição mais equili ibrada e uma desaceleração do êxodb rural. Os ecossistemas secos são altamente vulneráveis às intervenções no meio. Quando sujeitos a intervenções que não se coadunam com as suas características e limites, evoluem rapidamente para estados de desequilíbrio ambiental, acelerando as processos erosivos e lesandb gravemente o rearsso solo.

Vários estudas efectuadas em diversas partes do mundo em ecossistemas secas, tem demonstrado que o abandono de campos agrícolas não resolve o problema da desert ificação, tanto em áreas de regadio, como em áreas de sequeiro. Bem pelo contrário.

\section{Conclusão}

Em Cabo Verde, os problemas relacionados com a agricultura de sequeiro e com a de regadio, exigem actuações diferenciadas de forma a aumentar a produção e a ultrapassar os problemas de perda de produtividade.

Ao nível da agricultura de sequeiro, a uti lização de socalcos exige muito esforço humano, não só na edificação, como também na manutenção dos muros. No entanto, o papel no combate à erosão e consequente perda de solo tem sido particularmente positivo. Após a ocorrência de chuvadas intensas, na grande maioria das vertentes, o papel destas estruturas tem sido muito positivo no controlo da erosão e na formação de ravinas. Apenas em alguns casos, foram necessários trabalhos de recuperação dos muros.

O papel de actividades que completam a actividade agrícola é particularmente importante para a economia e bem-estar da população. Aumentam os lucros e, por outro lado, exercem-se actividades durante todb o ano. O artesanato tem vindo a assumir um papel importante na concretização deste objectivo, embora deva estar mais conectado com os mercados locais, regionais e intemacionais.

Ao nível das áreas de agricultura de regadio, o processo de salinização é frequente, principalmente em São Vicente, nas ribeiras da Vinha e de Jilião. As consequências são graves e culminam no abandono das propriedades agrícolas.

A utilização da ETAR da Vinha, em São Vicente, tem permitido o aumento do número de explorações e o aumento da produção. A construção de novos reservatórios é fundamental para o desenvolvimento deste tipo de agricultura, permitindb ainda a redução de desperdício de águas pluviais para o mar durante a época das chuvas. A par, politicas de investimento em sistemas de rega, nomeadamente, o de gotejamento, são muito importantes. Embora o investimento inicial seja elevado irá permitir uma optimização dos gastos hídricos e contribuir fortementena luta contra fenómenos de desertifificação.

\section{Referências bibliográficas:}

Avrral, Ilídio (1964) - Santiago de Cabo Verde. A Terra e os Homens. Lisboo, Junta de Investigações do Ultramar, Memórias, n 48, 444 p.+ LXXI Estampas e XI Mapas extratexto.

Dins, A. e Marros, G. (1994) - "Carta de Zonagem Agro-Ecológica e da Vegetação de Cabo Verde. VI - Ilha de São Vicente", Garcia de Orta, Sér. Botânica, Lisboca, 12 (1-2) , p.69-100. 
FERAJIRA, Denise Bnum (1983) - Étude de la convection au-dessus de l'atlantique tropical au large de I 'Afrique occidental. Linha de acção de Geografia Física, Relatório n¹6, Lisboa, CFG, INIC, $37 \mathrm{p}$.

FasEcA, H. (1962) - "Contribuiçãa para o estudo do problema biocl imático do mil ho em Cabo Verde" . Boletim de Propaganda e Informação, Ano XIII, n¹56, p.44-57.

FOURNIER (1962) - Carte du danger d'erosion en Afrique e sud du Sahara. CEE-CCIA.

Instriuto Nactanal de ESTATÍSTICA (1998) - Estatísticas demográficas, cabo Verde.

KrसBr, A. (1973) - The use of land and hater resaurces in the past and present valley of Caxaca, Mexico. Prehistory and human ecology of the valley of Caxaca. Vol. 1, Ann Arboor, Memoirs of Museum of Antropology, University of Michigan, $n^{\circ} 5$.

LAncBein e Sarum (1958) - "Yield of sediment in relation to mean amual precipitation". Trans. Amer. Geophys. Union, 39, p.1076-1084.

Larex̦ç, Luciano (coordenador) (2006) - Paisagens de Socalcos e Riscas Naturais em Vales do Rio Alva. NICIF, Faculdade de Letras da Universidade de Coimbra, $192 \mathrm{p}$.

REBELO, Fernando (1982) - "Considerações metodblógicas sobre o estudo dos ravinamentos". Commicações. II colóquio Ibérico de Geografia, Lisboa, 1980, Volume I, p. 339-350.
RekBe, Fernando (1999) - "Riscos de inundação rápida em Cabo Verde. Apontamentos de observação numa breve visita à Praia e ao Mindelo". Finisterra, Iisboca, 34 (67-68) , p. 47-55.

Rebejo, Fernando; CunHa, Lúcio; Cordetro, A. M. Rochette (1986) - "Sobre a origem e evolução actual dos ravinamentos em calcários margosos na área de Condeixa". Actas, IV Colóquio Ibérico de Geografia, Coimbra, p. 875-881.

SEPA (2000a) - Livro Branco sobre o Estado do Ambiente em Cabo Verde. Ministério da Agricultura, Alimentação e Ambiente. Secretariado Executivo Para o Ambiente SEPA, Praia (República de Cabo Verde).

SEPA (2000b) - Planificação e ordenamento dos rearsos naturais da Reajiblica de Cabo Verde. Cabo Verde Natura 2000. Secretariado Exeautivo para o Ambiente SEPA, Praia (Republica de Cabo Verde).

ThORNIHWAIIE, C. (1948) - "An approach towards a rational classification of climate". Ceographical Rewiew, 38, p.55-94.

WhAFAN, A. e MATras, J. (1992) - "Mudança ecológica e desertificação". Desertificação: causas e consequências, Lisboa, Fundação Calouste Gulbenkian, p. 265-407.

WHFITIKRR, R. (1970) - Communities and ecosystems. London, Macmillan, p.158. 